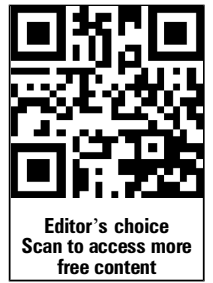

${ }^{1}$ Division of Adult Congenital and Valvular Heart Disease, University Hospital Muenster, Muenster, Germany ${ }^{2}$ Institute for Molecular and Translational Therapeutic Strategies (IMTTS), Hannover Medical School, Hannover, Germany

${ }^{3}$ Centre for Clinical and Basic Research, IRCCS San Raffaele, Rome, Italy

\section{Correspondence to}

Dr Robert M Radke, Division of Adult Congenital and Valvular Heart Disease, Department of Cardiology and Angiology, University Hospital Muenster, Albert-Schweitzer-Campus 1, Münster 48149, Germany; robert.radke@ukmuenster.de

Received 19 February 2014 Revised 10 June 2014 Accepted 9 July 2014 Published Online First 5 August 2014

\section{SLinked}

http://dx.doi.org/10.1136/ heartjnl-2014-306257

\section{CrossMark}

To cite: Radke RM, Diller G-P, Duck M, et al. Heart 2014;100: 1696-1701.

\title{
Endothelial function in contemporary patients with repaired coarctation of aorta
}

\author{
R M Radke, ${ }^{1}$ G-P Diller, ${ }^{1}$ M Duck, ${ }^{1}$ S Orwat, ${ }^{1}$ D Hartmann, ${ }^{2}{ }^{T}$ Thum, ${ }^{2,3}$ \\ H Baumgartner ${ }^{1}$
}

ABSTRACT

Objective Previous studies have suggested endothelial dysfunction in adult patients after repair of aortic coarctation (CoA). It has been proposed to play a key role in the pathogenesis of arterial hypertension in the absence of re-coarctation. We aimed to assess the presence of endothelial dysfunction, the number of endothelial progenitor cells (EPC), and the levels of proinflammatory cytokines associated with endothelial injury in contemporary patients after $\mathrm{CoA}$ repair.

Methods For this prospective observational study, 20 CoA patients and 22 healthy controls were recruited. Digital reactive hyperaemia was measured by peripheral arterial tonometry. Flow cytometry was used to quantify $E P C s$, and a comprehensive panel of laboratory markers of endothelial dysfunction was measured.

Results Half the patients had known arterial hypertension requiring medical treatment. Indices of reactive hyperaemia showed no significant difference between CoA patients (1.96 \pm 0.32$)$ and controlss (1.765 $\pm 0.48)(\mathrm{p}=0.82)$. Circulating $E P C s$, defined by the number of $\mathrm{CD}_{3} 4^{+}, \mathrm{CD}^{4} 4^{+} / \mathrm{KDR}^{+}, \mathrm{CD} 34^{+} / \mathrm{AC} 133^{+}, \mathrm{CD}^{2} 4^{+} / \mathrm{AC} 33^{+} /$ $\mathrm{KDR}^{+}$or $\mathrm{CD} 4^{+} / \mathrm{CD} 5^{-}$labelled cells were equally not significantly different between the groups. Furthermore, plasma levels of inflammatory mediators and markers of endothelial function (IL-6, IL-8, ICAM1 and VCAM1) were not significantly different between the groups, as were vascular endothelial growth factor levels ( $p>0.05$, for all). Conclusions By contrast with earlier reports, no clinically significant difference in endothelial function between adult patients with coarctation repair and healthy controls could be demonstrated. Therefore, endothelial dysfunction may not necessarily be present in this population. Further studies are required to identify mechanisms and to develop strategies to avoid arterial hypertension in these patients.

\section{INTRODUCTION}

Despite surgical or interventional repair in early life, the prevalence of hypertension in adult patients with aortic coarctation in the absence of re-coarctation remains high, and is associated with an increase in cardiovascular morbidity and mortality. ${ }^{1}$ As many as $50 \%$ of patients aged between 30 years and 40 years may be hypertensive. ${ }^{2}$ The mechanisms of hypertension in these patients remain largely unclear. As a consequence, coarctation of the aorta is increasingly viewed as a systemic cardiovascular disorder rather than a localised disease of the descending aorta. Endothelial dysfunction is an important component in the development of cardiovascular disease, and has been proposed to play a key role in the pathogenesis of arterial hypertension in patients after coarctation repair. ${ }^{3}$ Other studies however, have questioned the presence of endothelial dysfunction in this setting. ${ }^{45}$ Multiple methods and markers related to endothelial function have been evaluated which are thought to measure different aspects of a complex system. In addition to differences in patient populations, these methodological differences may have contributed significantly to conflicting results.

In this study of endothelial function, a combination of tests on a vascular, cellular and biochemical level was selected. For the non-invasive measurement of endothelial function, we chose peripheral arterial tonometry (PAT) over flow-mediated dilation (FMD). While widely used, measuring FMD requires a considerable amount of operator training and experience which may influence the feasibility and reproducibility of measurements in a clinical setting. Also, protocols, imaging parameters, data analysis and interpretation of results have been quite heterogeneous, complicating the comparability of outcomes. ${ }^{6}$ Meanwhile, measurements of reactive hyperaemia (RH) by PAT are increasingly being used. The U.S. Food and Drug Administration (FDA)-approved EndoPAT unit features a simple setup and a standardised protocol. Measurements and data analysis are largely automated, easy to perform and have a good reproducibility. ${ }^{7} \mathrm{RH}$ measurements have been shown to correlate with endothelial function as measured by injection of acetylcholine, ${ }^{8}$ and to independently predict major cardiovascular events. ${ }^{9}$

Endothelial function is influenced by the balance of endothelial injury and recovery. Proinflammatory cytokines (such as IL-6, IL8 and MCP-1) may impair endothelial function by reducing nitric oxide synthesis in endothelial cells. ${ }^{10}$ They may also increase production of adhesion molecules (such as VCAM1 and ICAM1) stimulating the migration of leukocytes into the vascular wall in atherogenesis. Measurements have been used for cardiovascular risk prediction. ${ }^{11}$ Circulating endothelial progenitor cells (EPC) from the bone marrow contribute to the replacement of injured endothelial cells, and their number is related to endothelial function and cardiovascular risk. ${ }^{12}$ Vascular endothelial growth factor (VEGF) is a potent angiogenic factor stimulating the mobilisation of EPCs from the bone marrow, and reduced levels may be involved in the development of endothelial dysfunction. ${ }^{13}$

Using this comprehensive panel of previously employed tests, our objective was to study 
endothelial function, endogenous repair mechanisms and inflammatory injury in a group of contemporary patients after repair of aortic coarctation.

\section{METHODS}

\section{Study participants}

In this prospective observational study, 20 patients with coarctation repair who presented to our adult congenital heart disease centre between July and September 2009 were included. Twenty-two controls were recruited by providing information on the study through leaflets, the department's website and word of mouth (table 1). The protocol was approved by the local ethics committee, and all study participants provided written informed consent.

\section{Blood pressure and PAT}

Digital reactive hyperaemia was measured with PAT using a commercially available system (Endo-PAT, Itamar Medical, Caesarea, Israel). The examinations were carried out in a quiet room at $25^{\circ} \mathrm{C}$ with the patient in a supine position and probes placed on both index fingers. A blood pressure cuff was attached to the right arm and patients were allowed to rest and accommodate to temperature conditions for at least $15 \mathrm{~min}$. Blood pressure was measured using an auscultatory sphygmomanometer. After baseline measurements, the blood pressure cuff was inflated to $200 \mathrm{~mm} \mathrm{Hg}$ or at least $20 \mathrm{~mm} \mathrm{Hg}$ supra-systolic levels, while the effect of occlusion on tonometry was observed. After exactly $5 \mathrm{~min}$, the cuff was deflated. During the following $10 \mathrm{~min}$ of simultaneous tonometry of both index fingers,

Table 1 Patient characteristics

\begin{tabular}{|c|c|c|}
\hline & $\operatorname{CoA}(n=20)$ & Controls $(n=22)$ \\
\hline Age (years) & $35 \pm 13$ & $30 \pm 11$ \\
\hline Male/female & $16 / 4$ & $14 / 8$ \\
\hline BMI $\left(\mathrm{kg} / \mathrm{m}^{2}\right)$ & $25.0 \pm 4.2$ & $25.2 \pm 5.0$ \\
\hline Diabetes (\%) & 5 & 0 \\
\hline Hyperlipidaemia (\%) & 0 & 0 \\
\hline CAD (\%) & 0 & 0 \\
\hline Active smoker (\%) & 25.0 & 13.6 \\
\hline Renal insufficiency (\%) & 0 & 0 \\
\hline \multicolumn{3}{|l|}{ NYHA class (\%) } \\
\hline NYHA class I & 90 & 100 \\
\hline NYHA class II & 10 & 0 \\
\hline NYHA class III & 0 & 0 \\
\hline NYHA class IV & 0 & 0 \\
\hline Age at operation (years) & $7 \pm 6$ & - \\
\hline \multicolumn{3}{|l|}{ Type of operation (\%) } \\
\hline Patch & 35 & - \\
\hline End-to-end anastomosis & 40 & - \\
\hline Interposition of tube graft & 15 & - \\
\hline NA & 10 & - \\
\hline \multicolumn{3}{|l|}{ Medication (\%) } \\
\hline ACE-inhibitors & 30 & 0 \\
\hline ARB & 15 & 0 \\
\hline$\beta$-blockers & 20 & 0 \\
\hline$C C B$ & 5 & 0 \\
\hline Diuretics & 10 & 0 \\
\hline Statins & 5 & 0 \\
\hline
\end{tabular}

hyperaemic response was observed. Data were analysed automatically using Endo-PAT-2000-V.3.1.2 (Itamar Medical). The reactive hyperaemia index (RHI) of the occluded arm was calculated as the ratio between postocclusion and preocclusion PAT signals, and normalised to the results of the control arm (figure 1).

\section{Flow cytometric detection of circulating EPCs}

Blood was drawn immediately before measurement of digital reactive hyperaemia. Peripheral blood mononuclear cells (PBMNC) were isolated by density centrifugation with Vacutainer CPT cell preparation tubes (BD Biosciences, Oxford, UK) according to the manufacturer's instructions. EPCs were enumerated using established criteria as $\mathrm{CD} 34^{+}$cells coexpressing AC133 and VEGF receptor-2 (VEGFR2/fetal liver kinase 1/ KDR) or cells expressing CD34 and not CD45. ${ }^{14} 15$ We incubated $10^{6}$ PBMNCs with FITC-labelled monoclonal mouse antihuman CD34 (BD Bio-sciences), PE-labelled monoclonal mouse antihuman AC133 (Miltenyi Biotec, Surrey, UK), and allophycocyanin-labelled monoclonal mouse anti-human KDR (R\&D Systems, Abingdon, UK) antibodies for $30 \mathrm{~min}$ at $4^{\circ} \mathrm{C}$ according to the manufacturer's instructions, or with appropriate isotype controls. At least 100000 events were acquired in the lymphomonocytic gate using a FACSCalibur cytometer (Becton Dickinson, Oxford, UK).

Analysis was performed using FCS-Express-3 (De Novo Software, Los Angeles, USA). The number of progenitor cells was calculated as a percentage of all lymphomonocytic cells (figure 2). We also quantified EPCs as lymphomonocytic cells expressing CD34 with low expression of CD45 (PE-labelled monoclonal mouse antihuman CD45, BD Biosciences) as CD45 low/CD34 ${ }^{+}$EPCs in accordance with previous studies. ${ }^{16}$

\section{Plasma assays}

Plasma levels of interleukin-6 (IL-6), interleukin-8 (IL-8), intercellular adhesion molecule 1 (ICAM-1), vascular cell adhesion molecule 1 (VCAM1), monocyte chemotactic protein-1 (MCP1) and VEGF, were quantified using a bead array cytometric analyser (Luminex System, Luminex Corporation, Austin, Texas, USA) and multiplex bead kits (Bio-Rad Laboratories, Inc., Hercules, California, USA) according to the manufacturer's instructions.

\section{Echocardiographic parameters}

A comprehensive standardised echocardiographic evaluation was performed in all patients using a Vivid 7 Ultrasound Machine (GE Healthcare, Little Chalfont, UK). LV mass was calculated from linear dimensions obtained from M-mode images. ${ }^{17}$ Relative wall thickness was calculated as: $(2 \times$ posterior wall thickness)/end-diastolic diameter. The aortic arch and descending aorta were visualised from a suprasternal view. Doppler echocardiography was used to measure the peak blood flow velocity (Vmax) at the former coarctation site. Diastolic run-off was defined as continuous forward flow throughout the whole diastole.

\section{Statistical analysis}

Data are expressed as mean \pm SD. Power calculation was performed using G*Power-3.1 (University of Duesseldorf, Department of Psychology, Duesseldorf, Germany) assuming a clinically meaningful difference in mean RHI of $0.4(22 \%)$ on the basis of previous studies $^{8} 18$ and a SD of 0.5 and showed a power $(1-\beta$ error probability) of 0.83 with the sample size ( $\alpha$ error probability 0.05 ). 
Figure 1 Examples of normal $(A)$ and abnormal (B) peripheral arterial tonometry traces. Traces represent volume changes at the tip of both index fingers over the time course of blood pressure cuff, blood flow is interrupted in the right index finger (probe 2). In normal individuals, deflation of the cuff leads to marked reactive hyperaemia, while in patients with an impaired endothelial function the increase of the amplitude is much smaller. the recording. During inflation of the

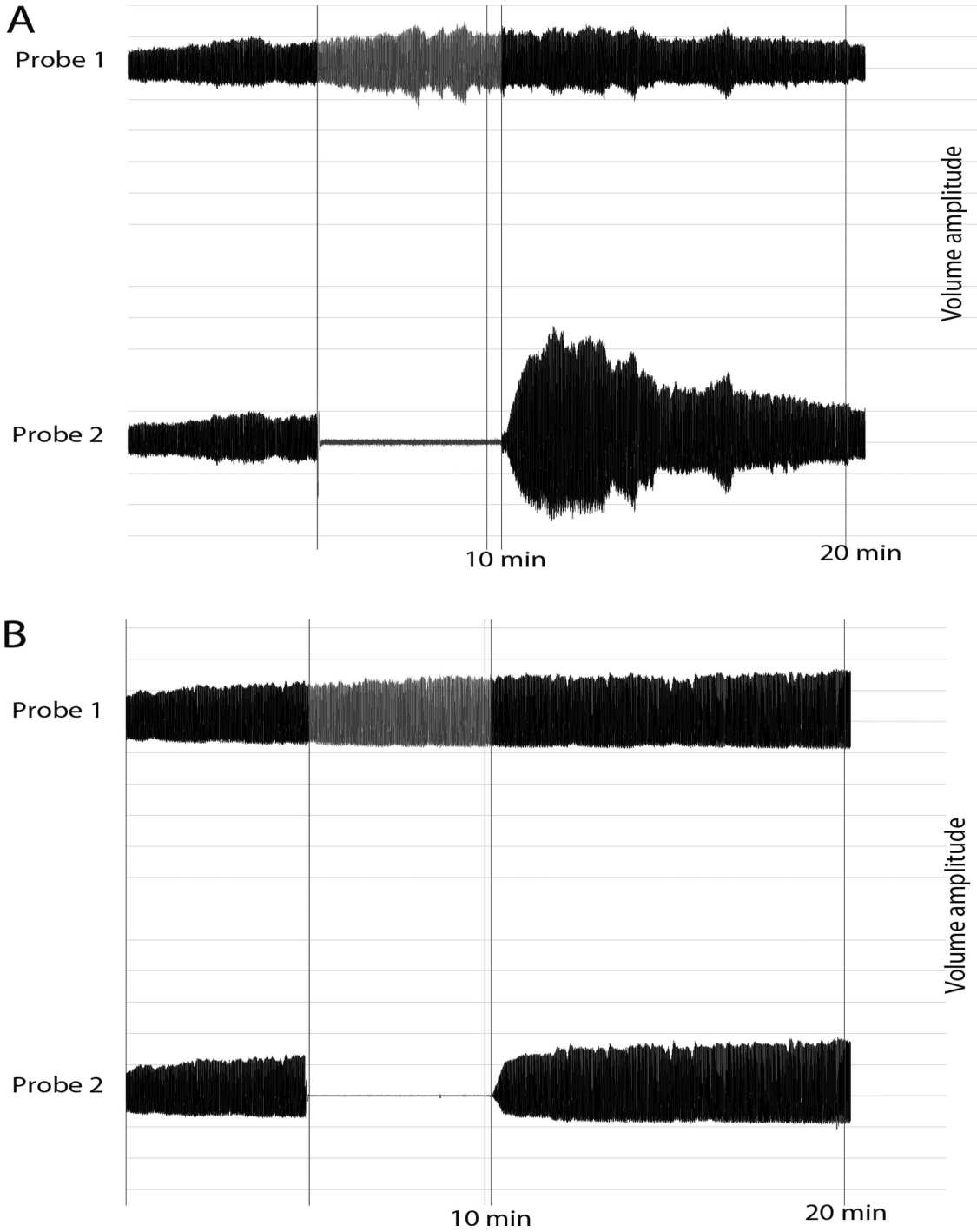

Statistical analysis was performed with the Mann-Whitney U test or $t$ test (depending on the distribution of values) and $\chi^{2}$ test were appropriate using GraphPad Prism V.5.0 (GraphPad Software, San Diego, California, USA). For all analyses, a 2-sided value of $\mathrm{p}<0.05$ was considered statistically significant.

\section{RESULTS}

Twenty patients with coarctation of the aorta who had undergone surgical treatment in childhood were recruited. The mean age at surgery was $7 \pm 6$ years. Only five patients were older than 9 years at the time of surgery. Half the patients had known arterial hypertension requiring antihypertensive treatment. Medical treatment had been started at least 3 years prior to enrolment. There was no significant difference in age or Body Mass Index between patients and controls. They also did not significantly differ in gender $\left(\chi^{2}(1, \mathrm{~N}=42)=1.16, \mathrm{p}=0.3\right)$ or the number of smokers $\left(\chi^{2}(1, N=42)=2.6, p=0.1\right)$. One of the patients had type I diabetes. None of the patients or controls had a history of coronary artery disease or stroke, or had any clinical signs of infection. Details on patient characteristics are presented in table 1 .

Systolic ambulatory blood pressure was significantly higher in CoA patients, while diastolic pressure showed no significant difference between patients and controls. At the time of measurements, two patients showed signs of significant residual stenosis (as defined by a blood pressure gradient $>20 \mathrm{~mm} \mathrm{Hg}$ between upper and lower limbs and diastolic run-off), which required subsequent intervention. Two patients had a LV mass index greater than $125 \mathrm{~g} / \mathrm{m}^{2}$, and 8 a relative wall thickness above 0.45 . The mean values were in the normal range (table 2 ).

\section{Peripheral arterial tonometry} endothelial function as defined by reactive hyperaemia between patients and controls (RH-index $1.96 \pm 0.32$ vs $1.77 \pm 0.48$, $\mathrm{p}=0.82$ ) (figure 3). Also, we found no significant difference in RHI between hypertensive and normotensive patients. When patients were divided in groups with early versus late surgical repair using various age cut-offs, again, no significant difference could be found.

\section{Circulating EPC numbers}

Circulating EPC numbers, as defined by the number of $\mathrm{CD} 34^{+}$, $\mathrm{CD}_{3} 4^{+} / \mathrm{KDR}^{+}, \mathrm{CD} 34^{+} / \mathrm{AC} 133^{+}$or $\mathrm{CD} 34^{+} / \mathrm{AC} 133^{+} / \mathrm{KDR}^{+}$ labelled cells did not significantly differ between patients and controls. Similarly progenitor cell numbers, defined as $\mathrm{CD} 34^{+} /$ CD45- labelled cells, showed no significant difference between CoA patients and controls (figure 3 ). We could not demonstrate
We could not demonstrate a clinically significant difference in 

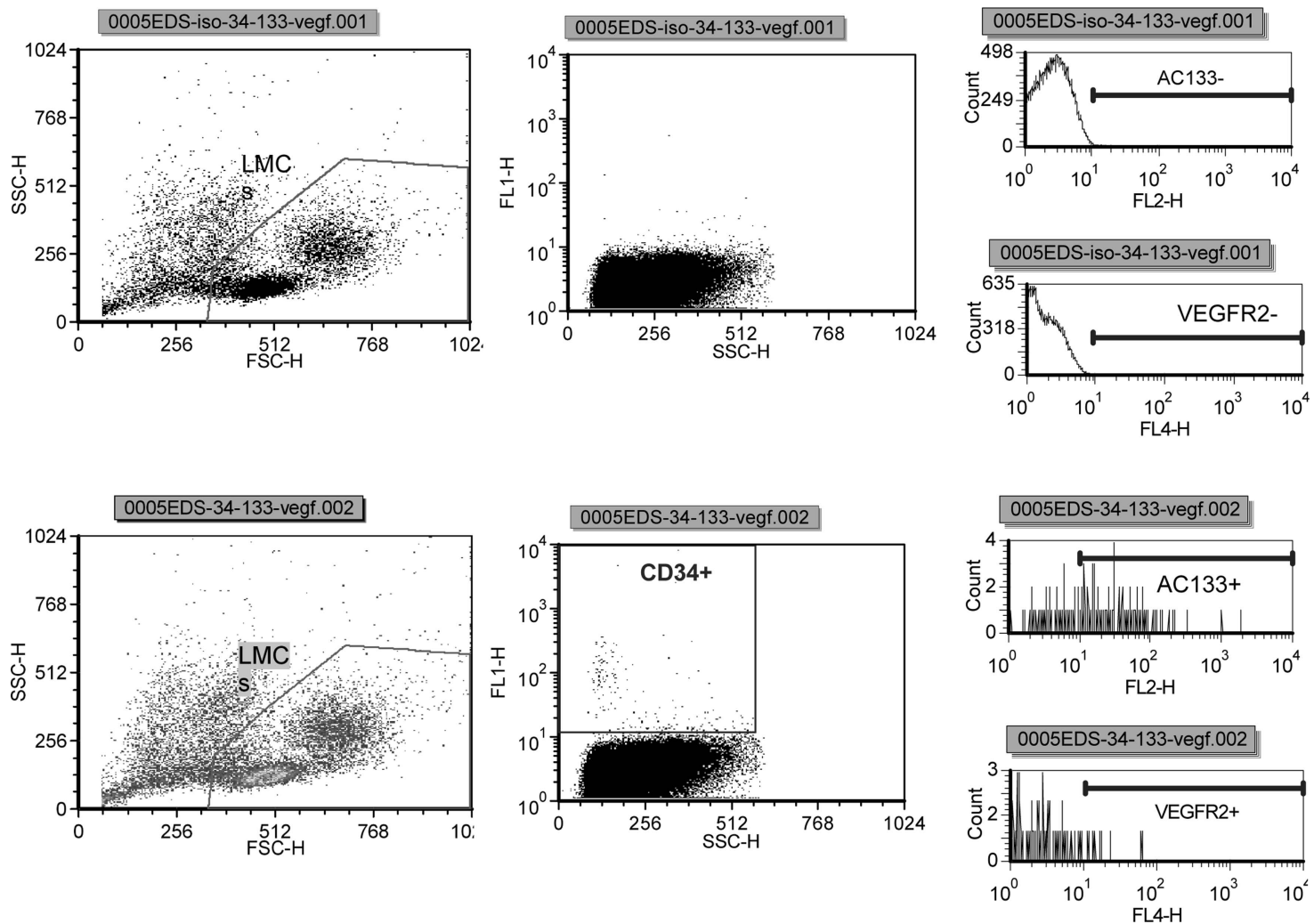

Figure 2 Example of a Fluorescence-activated cell sorting (FACS) cytometric analysis of peripheral blood mononuclear cells in one patient. The number of progenitor cells is calculated as a percentage of all lymphomonocytic cells.

a significant difference in EPC numbers between normotensive and hypertensive patients.

\section{Inflammatory markers}

Serum levels of sICAM, IL-6, IL-8 and VEGF did not show a significant difference between patients and controls $(p>0.05$ for all). Although there was a trend towards an increased level of sVCAM in patients, only levels of MCP-1 showed a significant difference between controls and CoA patients (table 3 ).

\section{DISCUSSION}

Arterial hypertension remains a common problem after coarctation repair, and is a major concern in the long-term outcome of

Table 2 Haemodynamic and echocardiographic parameters

\begin{tabular}{lcl}
\hline & $\begin{array}{l}\text { CoA } \\
(\mathbf{n}=20)\end{array}$ & $\begin{array}{l}\text { Controls } \\
(\mathbf{n}=\mathbf{2 2})\end{array}$ \\
\hline Haemodynamic parameters & & \\
$\quad$ Systolic BP (mm Hg) & $131.6 \pm 14.1^{*}$ & $119.1 \pm 7.5$ \\
Diastolic BP (mm Hg) & $79.0 \pm 8.3$ & $81.2 \pm 7.5$ \\
Blood pressure difference between upper and & $10.0 \pm 14.7$ & - \\
lower extremities (mm Hg) & & \\
Echocardiographic parameters & $105.7 \pm 16.9$ & - \\
LV Mass Index (g/m ${ }^{2}$ ) & $0.4 \pm 0.1$ & - \\
Relative wall thickness & $2.2 \pm 0.8$ & - \\
Vmax (m/s) & & \\
\hline * $\mathrm{p}<0.05$ versus controls; Vmax, peak blood flow velocity $(\mathrm{Vmax})$ at the former \\
coarctation site. & & \\
BP, blood pressure. & &
\end{tabular}

these patients. The pathophysiology of hypertension after successful surgical treatment of aortic coarctation, and in the absence of re-coarctation is still poorly understood. It has been suggested that coarctation of the aorta could represent a primary or secondary systemic vasculopathy rather than an isolated local disease of the aortic isthmus. These changes are thought to be involved in the development of hypertension in the absence of re-coarctation as well as premature cardiovascular events.

A number of observational studies in patients after coarctation repair have proposed endothelial dysfunction as measured by FMD, or a decreased reactivity to nitric oxide of the arterial wall as a key player in this respect. ${ }^{3}{ }^{19-22}$ Impairment of FMD in these patients has been described with ${ }^{20}$ and without evidence of increased blood pressures. ${ }^{3}$ This has lead to the hypothesis that endothelial dysfunction may not simply be the result, but partly the cause of hypertension in the absence of re-coarctation. The findings of persistent impaired endothelial function proximally, but not distally, to the former coarctation site, ${ }^{19} 23$ as well as association of endothelial dysfunction with age at repair, ${ }^{21}$ suggest that the former pressure gradient across the coarctation may be a mechanism inducing structural and functional changes including endothelial dysfunction. Proinflammatory cytokines and soluble adhesion molecules associated with endothelial function have been found to be increased even in normotensive patients ${ }^{3} 24$ and point towards an ongoing endothelial injury. However, a number of investigators have recently reported preserved endothelium-dependent vascular reactivity in contemporary patients after coarctation repair ${ }^{4525}$ and have found serum markers of endothelial dysfunction (Endothelin-1) not to be significantly elevated compared with controls. ${ }^{24}$

The current study investigated contemporary patients with coarctation repair and adequate blood pressure-albeit with a relatively high proportion of patients on antihypertensive 
A

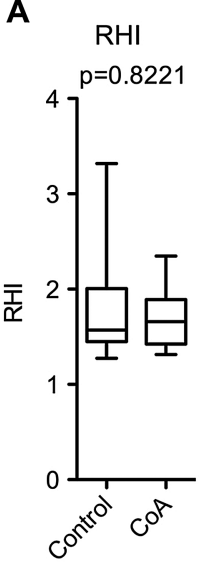

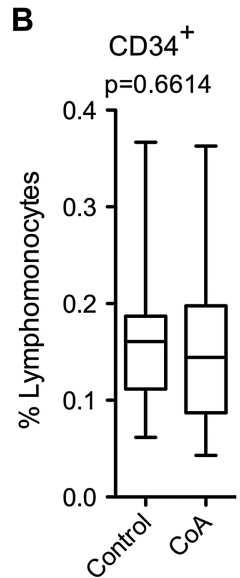
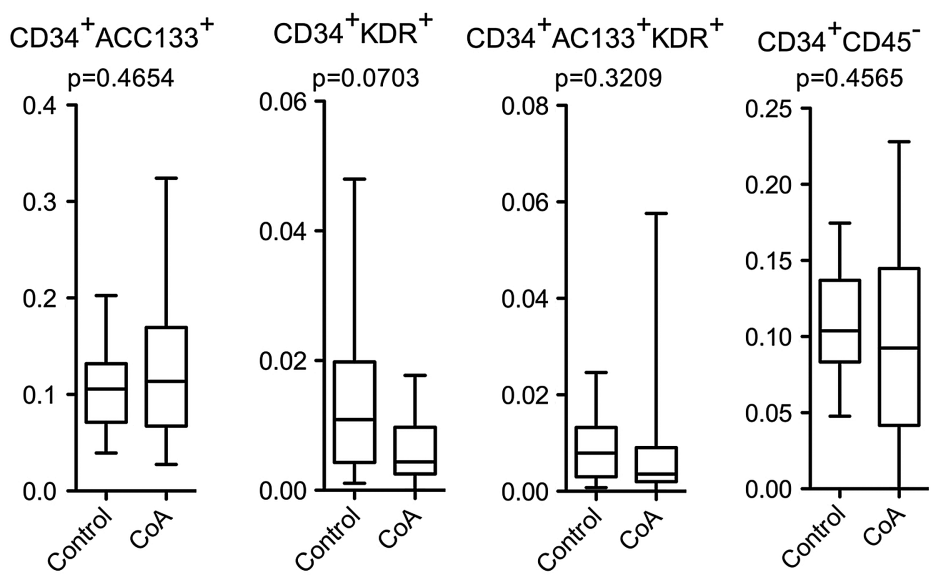

Figure 3 (A) Relationship between reactive hyperaemia indices measured by peripheral arterial tonometry in patients with coarctation repair (CoA, $\mathrm{n}=20)$ versus healthy individuals (controls, $n=22$ ). (B) Comparison of the number of progenitor cells defined by different criteria and expressed as a percentage of all lymphomonocytic cells in patients with coarctation repair (CoA, $n=19)$ versus healthy controls $(n=21)$. Data are presented in box plots.

medication. In a study powered to detect previously described meaningful clinical differences in RHI, we could not demonstrate a significant difference in endothelial function as assessed by PAT between patients and healthy controls. Consistent with this finding, numbers of EPCs, soluble forms of adhesion molecules, and all but one serum level of proinflammatory markers did not show a significant difference. The consistent finding of preserved endothelial function on a molecular, cellular and vascular level (investigated for the first time as part of a single study) suggest that a clinically relevant endothelial dysfunction may not be present in our population.

In some regards, the patients included in the current study may represent the better end of the spectrum of patients. The mean age at surgery in our population was $7 \pm 6$ years. While some investigators have shown evidence for endothelial dysfunction even in patients operated at a very young age, ${ }^{23}$ others have found normal FMD in patients younger than 9 years of age at coarctation repair. ${ }^{21}$ Also, $\mathrm{LV}$ mass has been shown to relate to the time to correction as well as systolic blood pressure in coarctation patients. ${ }^{20}$ LV hypertrophy was present in only $10 \%$ of our patients.

While a preserved endothelial function in our normotensive patients would be consistent with recent findings of others, ${ }^{425}$ the percentage of hypertensive patients was high in our patient group. In these patients, antihypertensive treatment resulted in good blood pressure control, and had been initiated at least 3 years prior to enrolment. It seems possible that early and rigorous use of antihypertensive medication in the current era may have, in part, prevented peripheral vascular and myocardial damage. Two recent prospective drug trials in patients after coarctation repair have provided evidence that impairment of endothelial function may, in

Table 3 Levels of serum markers

\begin{tabular}{lcc}
\hline & CoA $(\boldsymbol{n}=\mathbf{1 9})$ & Controls $(\mathbf{n}=\mathbf{2 1})$ \\
\hline sICAM1 $(\mathrm{ng} / \mathrm{mL})$ & $143.361 \pm 66.224$ & $127.875 \pm 46.726$ \\
sVCAM1 $(\mathrm{ng} / \mathrm{mL})$ & $128.934 \pm 24.275$ & $113.279 \pm 32.153$ \\
IL6 $(\mathrm{pg} / \mathrm{mL})$ & $4.142 \pm 2.478$ & $3.412 \pm 2.370$ \\
IL8 $(\mathrm{pg} / \mathrm{mL})$ & $4.347 \pm 2.761$ & $3.478 \pm 4.038$ \\
MCP-1 $(\mathrm{pg} / \mathrm{mL})$ & $70.10 \pm 37.46^{*}$ & $46.54 \pm 27.75$ \\
VEGF $(\mathrm{pg} / \mathrm{mL})$ & $195.6 \pm 129.4$ & $178.3 \pm 07.1$ \\
\hline Serum levels of sVCAM, sICAM, IL-6, IL-8 and VEGF were similar in patients and \\
controls (p>0.05 for all). Patients had a significant higher level of MCP1 ( $\left.{ }^{*} \mathrm{p}<0.05\right)$. \\
VEGF, vascular endothelial growth factor.
\end{tabular}

fact, be reversible. Four weeks of treatment with an ACE inhibitor $^{26}$ or a HMG-CoA reductase inhibitor ${ }^{27}$ resulted in markedly increased FMD, while levels of proinflammatory cytokines and soluble adhesion molecules decreased.

In the light of our results, it appears that other mechanisms of hypertension in the absence of re-coarctation must also be considered: increased stiffness of the aorta and the carotid arteries have been demonstrated by several studies. ${ }^{23}{ }^{24}$ Aortic coarctation patients have been found to have histological changes of the aortic wall including fibrosis, cystic media necrosis and fragmentation of elastic fibres. ${ }^{28}$ De-differentiation of arterial smooth muscle and medial thickening have been described in animal models of coarctation, and provide possible explanations for the functional changes. Finally, the elastic properties of the aorta can also be altered by replacing elastic vessel tissue with stiff foreign material. In a study on the impact of aortic stenting in coarctation patients with significant stenosis, those with tube graft implantation showed little improvement in arterial hypertension despite successful reduction of the gradient. ${ }^{29}$

\section{Study limitations}

It might be considered a limitation of this study that measurements of FMD were not included. Considerations of standardisation, reproducibility and feasibility in our clinical setting have led us to choose PAT, which has recently emerged as an alternative technique.

In general, endothelial dysfunction is considered a systemic condition because evidence has been found in many vascular beds from the coronary arteries to the peripheral arteries and the microvasculature. Non-invasive peripheral measurements with FMD and PAT show a correlation with coronary endothelial function, but some differences have to be noted: while FMD is thought to be more related to conduit artery function, PAT may represent microvascular function to a higher degree. ${ }^{30}$ Also, alterations in vascular structure and function may not be uniformly distributed throughout the vasculature proximal to the former coarctation site. In a recent study using an animal model of coarctation, a progression of vascular remodelling, beginning first in large elastic arteries and delayed in distal vessels was found. It is thus possible that measurements of FMD would have yielded different results in our study. Even though microvascular function has been postulated to be an earlier indicator of cardiovascular risk especially in young patients, the value in coarctation patients remains to be determined. ${ }^{30}$ 
Finally, increasing the size of the sample may have exposed more subtle differences between the groups, albeit these may not be of clinical relevance.

\section{CONCLUSION}

By contrast with earlier reports, no clinically significant difference in endothelial function between adult patients with coarctation repair and healthy controls could be demonstrated.

Our findings on a molecular, cellular and vascular level suggest that aortic coarctation may not necessarily be associated with endothelial dysfunction in adult coarctation patients as seen at tertiary centres. Further studies are required to identify mechanisms and to develop strategies to avoid arterial hypertension in these patients.

\section{Key messages}

\section{What is already known on this subject?}

The prevalence of arterial hypertension in adult patients with aortic coarctation remains high and is associated with an increase in cardiovascular morbidity and mortality. Endothelial dysfunction has been proposed to play a major role in the pathogenesis of hypertension in the absence of re-coarctation in these patients.

\section{What might this study add?}

The results of the current study demonstrate that endothelial dysfunction - as assessed by peripheral arterial tonometry, numbers of endothelial progenitor cells, soluble forms of adhesion molecules, and serum levels of proinflammatory markers - may not be inevitable in contemporary patients after coarctation repair.

\section{How might this impact on clinical practice?}

Our results are of clinical relevance as they demonstrate that aortic coarctation may not necessarily be associated with endothelial dysfunction in adult coarctation patients, as seen at tertiary centres. This underlines the possible importance of other mechanisms as potential causes of persistent arterial hypertension in the absence of re-coarctation. A better understanding of the involved mechanisms may at some point influence treatment decisions.

Contributors All authors have made substantial contributions to the manuscript. RMR and G-PD designed the study protocol. RMR, MD, DH and TT performed the measurements and lab work. Data analysis and writing was done by RMR and critically reviewed by G-PD and $\mathrm{HB}$.

Funding This study was supported by a research grant from the Fördergemeinschaft Angeborene Herzfehler Universität Münster e.V., Germany and a research grant from the Deutsche Forschungsgemeinschaft, Germany (DFG Th903/7-2).

\section{Competing interests None.}

Ethics approval Local Ethics Committee of the University of Muenster.

Provenance and peer review Not commissioned; externally peer reviewed.

\section{REFERENCES}

1 Toro-Salazar $\mathrm{OH}$, Steinberger J, Thomas W, et al. Long-term follow-up of patients after coarctation of the aorta repair. Am J Cardiol 2002;89:541-7.

2 Hager A, Kanz S, Kaemmerer $\mathrm{H}$, et al. Coarctation Long-term Assessment (COALA): significance of arterial hypertension in a cohort of 404 patients up to 27 years after surgical repair of isolated coarctation of the aorta, even in the absence of restenosis and prosthetic material. J Thorac Cardiovasc Surg 2007;134:738-45.
3 Brili S, Tousoulis D, Antoniades C, et al. Evidence of vascular dysfunction in young patients with successfully repaired coarctation of aorta. Atherosclerosis 2005; 182:97-103.

4 Swan L, Kraidly M, Vonder Muhll I, et al. Surveillance of cardiovascular risk in the normotensive patient with repaired aortic coarctation. Int I Cardiol

2010;139:283-8

5 Pressler A, Esefeld K, Scherr J, et al. Structural alterations of retinal arterioles in adults late after repair of aortic isthmic coarctation. Am J Cardiol 2010;105:740-4.

6 Thijssen DH, Black MA, Pyke KE, et al. Assessment of flow-mediated dilation in humans: a methodological and physiological guideline. Am J Physiol Heart Circ Physiol 2011;300:H2-12

7 Selamet Tierney ES, Newburger JW, Gauvreau K, et al. Endothelial pulse amplitude testing: feasibility and reproducibility in adolescents. J Pediatr 2009;154:901-5.

8 Bonetti PO, Pumper GM, Higano ST, et al. Noninvasive identification of patients with early coronary atherosclerosis by assessment of digital reactive hyperemia. J Am Coll Cardiol 2004:44:2137-41.

9 Akiyama E, Sugiyama S, Matsuzawa Y, et al. Incremental prognostic significance of peripheral endothelial dysfunction in patients with heart failure with normal left ventricular ejection fraction. J Am Coll Cardiol 2012:60:1778-86.

10 Cardaropoli S, Silvagno F, Morra E, et al. Infectious and inflammatory stimuli decrease endothelial nitric oxide synthase activity in vitro. $J$ Hypertens 2003;21:2103-10.

11 Aukrust $\mathrm{P}$, Yndestad $\mathrm{A}$, Smith $\mathrm{C}$, et al. Chemokines in cardiovascular risk prediction. Thromb Haemost 2007;97:748-54.

12 Shantsila E, Watson T, Lip GY. Endothelial progenitor cells in cardiovascular disorders. J Am Coll Cardiol 2007;49:741-52

13 Yla-Herttuala S, Rissanen TT, Vajanto I, et al. Vascular endothelial growth factors: biology and current status of clinical applications in cardiovascular medicine. J Am Coll Cardiol 2007:49:1015-26.

14 Valgimigli M, Rigolin GM, Fucili A, et al. CD34+ and endothelial progenitor cells in patients with various degrees of congestive heart failure. Circulation 2004:110:1209-12.

15 George J, Shmilovich H, Deutsch V, et al. Comparative analysis of methods for assessment of circulating endothelial progenitor cells. Tissue Eng 2006;12:331-5.

16 Numaguchi Y, Sone T, Okumura K, et al. The impact of the capability of circulating progenitor cell to differentiate on myocardial salvage in patients with primary acute myocardial infarction. Circulation 2006;114:1114-19.

17 Gottdiener JS, Bednarz J, Devereux R, et al. American Society of Echocardiography recommendations for use of echocardiography in clinical trials. J Am Soc Echocardiogr 2004;17:1086-119.

18 Davis JS, Yeo TW, Thomas JH, et al. Sepsis-associated microvascular dysfunction measured by peripheral arterial tonometry: an observational study. Crit Care 2009;13:R155.

19 Gardiner HM, Celermajer DS, Sorensen KE, et al. Arterial reactivity is significantly impaired in normotensive young adults after successful repair of aortic coarctation in childhood. Circulation 1994;89:1745-50.

20 de Divitiis M, Pilla C, Kattenhorn M, et al. Ambulatory blood pressure, left ventricular mass, and conduit artery function late after successful repair of coarctation of the aorta. J Am Coll Cardiol 2003;41:2259-65.

21 Heger $M$, Willfort $A$, Neunteufl T, et al. Vascular dysfunction after coarctation repair is related to the age at surgery. Int J Cardiol 2005;99:295-9.

22 Mizia-Stec K, Trojnarska O, Szczepaniak-Chichel L, et al. Asymmetric dimethylarginine and vascular indices of atherosclerosis in patients after coarctation of aorta repair. Int J Cardiol 2012:158:364-9.

23 de Divitiis $M$, Pilla C, Kattenhorn $M$, et al. Vascular dysfunction after repair of coarctation of the aorta: impact of early surgery. Circulation 2001;104:1165-70.

24 Moutafi AC, Alissafi T, Chamakou A, et al. Neurohormonal activity and vascular properties late after aortic coarctation repair. Int J Cardiol 2012;159:211-16.

25 Cuypers J, Leirgul E, Larsen TH, et al. Assessment of vascular reactivity in the peripheral and coronary arteries by Cine 3T-magnetic resonance imaging in young normotensive adults after surgery for coarctation of the aorta. Pediatr Cardiol 2013;34:661-9.

26 Brili S, Tousoulis D, Antoniades C, et al. Effects of ramipril on endothelial function and the expression of proinflammatory cytokines and adhesion molecules in young normotensive subjects with successfully repaired coarctation of aorta: a randomized cross-over study. J Am Coll Cardiol 2008;51:742-9.

27 Brili S, Tousoulis D, Antonopoulos AS, et al. Effects of atorvastatin on endothelial function and the expression of proinflammatory cytokines and adhesion molecules in young subjects with successfully repaired coarctation of aorta. Heart 2012:98:325-9.

28 Niwa K, Perloff JK, Bhuta SM, et al. Structural abnormalities of great arterial walls in congenital heart disease: light and electron microscopic analyses. Circulation 2001;103:393-400.

29 Eicken $A$, Pensl U, Sebening $W$, et al. The fate of systemic blood pressure in patients after effectively stented coarctation. Eur Heart J 2006;27:1100-5.

30 Flammer AJ, Anderson T, Celermajer DS, et al. The assessment of endothelial function: from research into clinical practice. Circulation 2012;126:753-67. 